\title{
Characterization and Determination of Briquette Fuel Prepared from Five Variety of Corn Cob
}

\author{
Gutu Birhanu Oliy ${ }^{*}$, Duresa Tesfaye Muleta \\ Renewable Energy Engineering Team of Bako Agricultural Engineering Research Centre, Oromia Agricultural Research Institute, Bako, West \\ Shoa, Ethiopia \\ Email address: \\ gtbr2006@gmail.com (G. B. Oliy), baerc2007@gmail.com (G. B. Oliy),Duresa2019@gmail.com (D. T. Muleta)
}

\section{To cite this article:}

Gutu Birhanu Oliy, Duresa Tesfaye Muleta. Characterization and Determination of Briquette Fuel Prepared from Five Variety of Corn Cob. International Journal of Sustainable and Green energy. Vol. 9, No. 3, 2020, pp. 59-64. doi: 10.11648/j.ijrse.20200903.11

Received: June 20, 2020; Accepted: July 24, 2020; Published: August 5, 2020

\begin{abstract}
Corn cob residue is significant potential for mere energy resource. From perspective of cost and air pollution management, exploitation of the residue fits appropriate into the strategy of sustainable development and environmentally friend. However, combusting of agricultural by-product without changing their physical nature is considered as insufficient and inefficient utilization to meet energy demand. Utilizing them in their natural form causes extensive heat loss and minimum of amount of heat energy can be recovered. Moreover raw corn cob residue has low density material and heating values when directly employed as fuel. So, converting it into a higher value energy resource is important issue. Corn cob was carbonized in carbonization technology with very limited supply of air. On drum part, about twelve holes were provided to follow up activity and boost carbonization process thereby to reduce charring time and increases conversion efficiency. After carbonization, carbonized corncob was withdrawn from reactor and charred products collected. The carbonized corn cob was crushed and grinded to fine particles in order to prepare briquette from five varieties. The briquettes were then removed from the mold and sun-dried in open air to maintain their mass. Briquette property and they calorific value were investigated employing standard methods. Thus, calorific value or HHV of BH-661, BH-541, Local, Shone and Limmu briquette were 28.58, 28.57, 27.60, 29.67 and $28.49 \mathrm{MJ} / \mathrm{Kg}$ respectively.
\end{abstract}

Keywords: Corn Cob, Carbonization, Briquette, Bulk Density, Proximate Analysis, HHV

\section{Introduction}

Energy is very important and cornerstone for economic and social development which brings remarkable alteration in any country. These development lead to major changes or shift particularly in utilizing the household energy sector. The growth rate of urban and rural populations mainly influenced type of fuel used and consumption pattern of energy. Energy consumption in rural areas of Africa is still low and is limited almost entirely to fuel wood [1]. According to Madon, 2000 [2] interviewed urban women in Ethiopia, Niger and Senegal did not like to cook with wood because they found it difficult to kindle, awkward, dangerous for children, smoky and messy.

According to Samson, 2000 [3] more than 90\% of the domestic energy requirement in Ethiopia is fulfilled by wood and other products associated with them which accelerate devastation of the forest resources. The way of processing biomass fuel as source of energy is very traditional and insufficient system where it cannot hit target of satisfying energy demand. Therefore, it is easy to guess how many tones of forest get destroyed for fuel purpose to meet the energy demand in the country. Moreover magnitude of energy used implies that energy consumption status in the country is inadequate for the survival and development requirements of its population.

Even though woody biomass has important benefits, its improper usage linked to adverse environmental effects such as deforestation, degradation of land and depletion of soil fertility. Thus, these adverse conditions have significantly affected agricultural production and productivity. However huge amount of agricultural residues are available which has big potential to offer energy from perspective of both cost and pollution management. An exploitation of these agricultural residue must fit well appropriate keen to environmental conservation policy.

However, burning or combusting of agricultural 
by-product without changing their physical nature is considered as insufficient and inefficient utilization to meet energy demand. Utilizing them in their natural form causes extensive heat loss and minimum of amount of heat energy can be recovered.

These losses because of their low heating value and air pollination problem $[4,5]$. This is because; most of these residues are low density materials $[6,7]$. Apart from these, their combustion cannot be effectively controlled [8]. Moreover due to their low bulk density, low heat release and the excessive amounts of smoke they produce while operation, utilization of them in their natural form as fuel is quite challenging [9]. These all physical characteristics create difficulty to use biomass residues in their raw form and make messy to handle, store, transport and utilize.

Therefore, converting agricultural by-product into higher value energy resource is so important. Because of extensive agricultural practices, significant amount of agricultural residues are available in substantial quantity. Despite their consideration as waste, agricultural residues such as rice husk, corn cob and groundnut husk become most promising choices as cooking fuels.

Briquette make technology is one of best method to improve thermal value of any biomass resource and its application so important and recently emerging skill $[9,10]$. Briquetting technology includes grinding of materials and then compaction of loose biomass to make best fuel and enhanced volumetric calorific value compared to the biomass in its original state [11].

Upgrading corncob residues to a high quality energy resource is an effective utilization of an underutilized agricultural waste. Corn cob residue in rare case is used as animal fodder and source of fuel for rural families [12]. However, majority of agrarian community in these areas usually consider the use value of the grain whereas they paid lesser attention for postharvest by-products [13]. Moreover farmers residing in maize belt area also engaged in the act of forest destruction in an attempt to find additional financial income by supplying the urban market with fire wood and wood charcoal.

Normally, conversion of agricultural residue can be performed with biological and thermochemical treatments. Thermochemical treatment is much more flexible because of high product yield and short processing time [14-16]. For high-efficiency conversion process, water-jacket carbonization technology is appropriate because of carbon monoxide emissions decreases and it's energy density increases throughout combustion [17].

Carbonization of corn cob pretends coal making process in order to produce char with high energy density through the omission of the energy-intensive process. As a matter of fact raw corn cob could be converted to energy density fuel by employing a simple carbonizing technology to make charred corn cob. At this point raw corn cob was made to be carbonized, in a very limited supply of atmospheric air and considerable shorten charring time. Thus, the activity was initiated with main aim to minimize problem associated with wood as fuel and to encourage local farmers to use briquette technology as important substituent for wood biomass which is considered to be mere energy resource.

\section{Material and Method}

\subsection{Material}

Materials which is important for manufacturing of corncob carbonization was identified \& selected based on the design specification. According to this, sheet metals, water pipe for handling and deformed bar are among materials used for construction of carbonizing technology. In addition to these, five varieties of corn cobs namely BH-661, BH-541, Local, Shone and Limmu, Clay Soil, Briquette press, are used for briquette making process. All raw corncobs utilized in this experiment were obtained from fields of farmers and local investors. These agricultural residues were mainly chosen because they are produced in large quantity in local areas and most often they were presented in widespread for local consumption and environmental pollution. Moreover technical instruments like Oven drier, Thermometer, Ballistic Bomb Calorific, Briquette Stove, Pan, Stop Watch and Digital Balance are employed for experiment test.

\subsection{Methodology}

\subsubsection{Corn Cob Sample}

Five varieties of raw corn cobs which are traditionally considered as wastes were collected from private investor and known farmers. These raw corn cobs were sorted out and dried over the sun so as to reduce the moisture content of the feedstock to ensure effective carbonization. The dried corn cobs were further categorized based on their distinct sizes to provide more surface or contact area for the carbonization activity. Basic density of corn cob was determined or estimated using plastic cylinder that was perfectly calibrated. The cylinder was packed with prepared samples and compacted well. Thus, the density was calculated employing standard formula.

\subsubsection{Fabricating of Carbonizer}

Modification of carbonization technology was implemented and continued as fellow. Consequently, drum part was manufactured by rolling $1.5 \mathrm{~cm}$ thickness sheet metal to $1.1 \mathrm{~m}$ diameter. On the drum parts, twelve holes were provided in order to facilitate carbonization of raw corn cob and checkup of carbonization processes. All these holes were $16 \mathrm{~mm}$ in diameter and suited on circumference of drum part. Exhaust chimney and coal tar box were prepared from sheet metal separately and then integrated to make one part.

The carbonizer is a simple cylindrical design fabricated to provide a means of creating low oxygen environment, it was fabricated using a drum of about $120 \mathrm{~cm}$ in height and 110 $\mathrm{cm}$ diameter with an opening at the top for loading the corn cobs feedstock. A suitable metal plate was constructed and 
was used as cover for the top opening of the drum during firing.

\subsubsection{Carbonization}

Corncob carbonizer was set in their working condition and then fuel material have been fed to reactor in batch to certain height of the drum. A fire ember was prepared outside the drum to be distributed over fuel material provided in carbonizer. After fuel reached required height, fire ember or glow were distributed evenly over raw fuel in order to facilitate carbonization activity per each batch. At the start of the carbonization process integrated part of exhaust chimney and lid was left open for the volatile gases to escape and collection of tar in middle cyclone. 16 metric diameter bolts were used on drum holes and slightly tightened in order to minimize tendency of complete combustion. The drum was closed eventually after application of the last batch \& change of the color of smoke has been checked up via upper lid. The lid was then closed thereafter; properly sealed to prevent air from entering. Because of application of the holes on the drum body, carbonization process got speed up. Enhancement of carbonization had been checked up throughout activity with the changing of the color of the smoke from black to white and eventually none. Corn cob was left to be carbonized for 90 to 120 minutes depending on season \& environmental condition. When the smoke releasing ceased or after it becomes colorless, top most lid that was integrated with chimney locked down and water get jacketed.

\subsubsection{Briquette Preparation}

The carbonized corn cob was crushed, grinded to fine particles using an electric milling machine. This fine particle was subjected to pass through $1 \mathrm{~mm}$ standard sieve to create homogenous particles throughout process. For case of binding material, natural organic binder was used or employed as binder. At this time clay soil was collected and dried over oven drier until moisture content get reduced or it's mass remained constant. The dried product was crushed and sieved employing standard method and kept in sealed containers until it was used. Finely pulverized char powder was added and poured into a mixing chamber and thoroughly agitated. The carbonized charred powder was mixed with binder in such a way that every particle of the carbonized material was coated with a film of the binder until thick black compound was obtained. The binder was fine clay soil and $20 \%$ clay soil concentration was applied to form briquettes. Clay soil mixed carbonized corn cob were pressed in electric operating briquette machine. The machine has four molds that was fabricated of steel pipes and had mold diameter of $12 \mathrm{~cm}$. The mixtures were introduced into a mold and electrically pressed to be compacted to a certain compaction rate. The briquettes were then removed from the mold and sun-dried in open air to a constant mass.

\subsubsection{Briquette Property}

Cylindrical briquettes were prepared in briquette molding machine. After the briquette was immediately ejected from machine, briquettes bulk density was measured. Bulk density of the briquettes were calculated from its mass, diameter and height. In order to maintain briquette durability and life, it was transferred to open air and kept at room temperature to balance moisture in side briquette with local environment. This helps to measure ability of briquette to withstand any destructive force occur while handling and transportation from place to place and enable to identify or determine compression force require during preparation the briquette. Briquette heating value or calorific values was determined employing Ballistic Bomb Calorimeter. Heating value of briquette normal measures maximum amount of energy potentially generated from burning of specific source. As whole, briquettes were manufactured from five variety of corn cob and their energy density were calculated and estimated.

\subsection{Proximate Analysis}

Proximate analysis of the briquettes were carried out to determine percentage moisture content, percentage volatile matter content, percentage ash content and percentage content of fixed carbon. The procedure of ASTM standard was implemented and asserted in order to estimate the above stated parameters.

\section{Results and Discussions}

\subsection{Carbonization of Corncob}

Once corncob carbonization was executed, carbonized corncob was removed over prepared carpet to further cool and safely collect charred from processed. The product was carefully withdrawn from reactor to further reduce damage and screening get performed so as to separate easily charred and uncharred cob. From this, charred and uncharred products were identified, sorted out and recorded to measure effectiveness of carbonizing technique. Mass of broken \& unbroken charred corn cobs were separated and measured to estimate quality and quantity of the charred products. Therefore volume based conversion rate of carbonization technology became $89.36 \%$ and an average one batch charring time acquired to be ranging from 100 to 120 minutes depending on season \& environment condition. Earlier carbonize technology deserved more time to make char and considerable carbonized lesser amount of biomass when compared with this one.

\subsection{Briquette Characterization}

\subsubsection{Bulk Density}

Average variation of bulk density of corn cob briquette was 494.56 to $520.01 \mathrm{~kg}$. m ${ }^{-3}$. BH-541 \& Shone had the highest density of 515.65 to $520.01 \mathrm{~kg}$. $\mathrm{m}^{-3}$ respectively, followed by Limmu $\left(510.35 \mathrm{~kg} . \mathrm{m}^{-3}\right)$ and $\mathrm{BH}-661\left(507.45 \mathrm{~kg} . \mathrm{m}^{-3}\right) \&$ lowest densities were observed for Local variety $(494.56 \mathrm{~kg}$. $\mathrm{m}^{-3}$ ). According to Kaliyan \& Morey, 2009 [18] briquetting of corn cobs or Stover can produce uniform products with bulk density of $500-600 \mathrm{~kg} . \mathrm{m}^{-3}$. In general balled or chopped corn stover are difficult to manage, transport, store and relatively used as compared to bare corn cob. 
Corn cob briquette is so easy to transport and stored because of its higher bulk density with mean value $520.01 \mathrm{~kg}$. $\mathrm{m}^{-3}$ than corncob charcoal whose bulk densities $389.0 \mathrm{~kg} . \mathrm{m}^{-3}$. The corn cob briquette is about $58 \%$ higher in calorific value than corncob char. According to Oladeji, 2011 [7] his work indicated that briquette produced from two varieties of corn cob became good biomass fuels. The corresponding maximum bulk densities of briquette produced from white and yellow corncob ranges $502-871 \mathrm{~kg} . \mathrm{m}^{-3}$.

In order to maintain durability and life of briquette, briquettes were transferred to open air and kept at room temperature to maintain moisture inside them. This helps to measure strength of briquette to withstand any destructive force occur during operation. Bulk density as well as calorific value of briquette were measured or estimated from the mass, diameter and height of the briquette and using calorimeter respectively.

However, above result show that corncob briquette has more positive attributes than agricultural residues briquette. In general, the higher the specific gravity of basic density of corn cob is, the greater the bulk density of its [19].

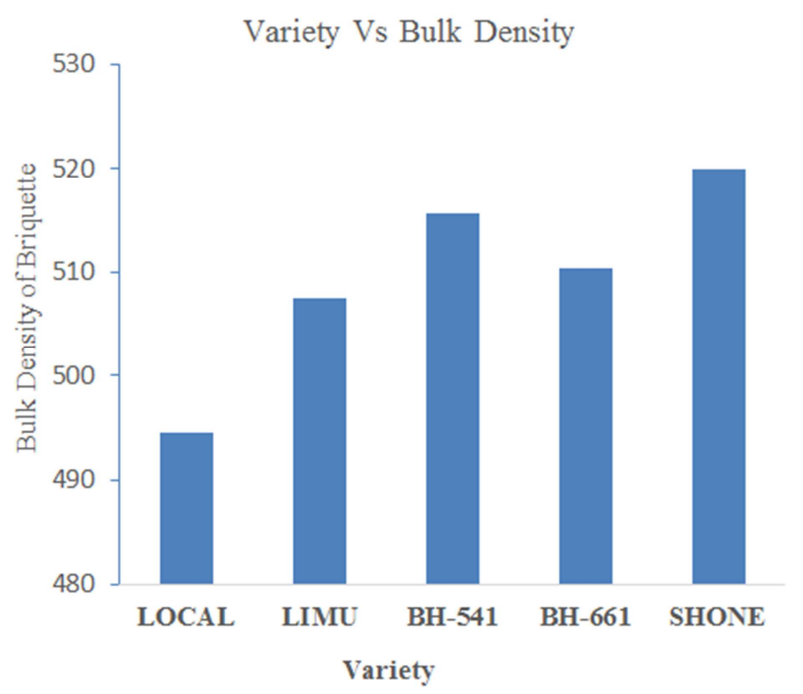

Figure 1. Mean Bulk Density of Corn Cob Briquette.

\subsubsection{High Heating Value (HHV)}

An average corn cob briquette high heating value $\mathrm{HHV}$ were among 27.60 and $29.67 \mathrm{MJ} \cdot \mathrm{kg}$. Briquette of charred corn cob of Shone showed the greatest HHV whereas BH-661, BH-541 and Limmu were statistically similar value whose HHV become $28.58,28.57$ and $28.49 \mathrm{MJ} \cdot \mathrm{kg}^{-1}$ respectively. Local variety has $27.60 \mathrm{MJ}$. $\mathrm{kg}^{-1}$ which showed the least performance for this property. The results are in agreement with the literature of Akintaro \& Musa, 2017 [20] who found $\mathrm{HHV}$ values among 30.67 to $31.52 \mathrm{MJ} \cdot \mathrm{kg}^{-1}$.

According to Adetogun \& Ogunjobi [21] as well as Oladeji \& Enweremadu, 2012 [22] high heating value of corn cob briquette is directly related to its fixed carbon content that increases with the apparent size and physical condition of corn cob. However, this association was observed in this study with few varieties, except for Shone, which showed the highest values for HHV and fixed carbon content.

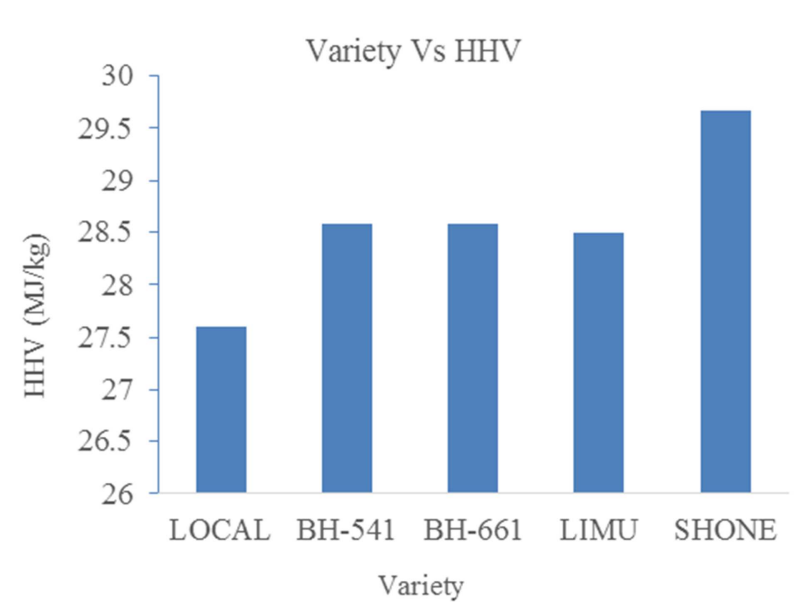

Figure 2. Mean HHV of Corn Cob Briquette.

Energy density was calculated or estimated from bulk density and heating value of biomass fuel. Figure 3 below illustrated mean variation energy density of five variety of corn cob briquettes. Energy density of the briquettes corn cob was expressed with Giga Joule. Briquette made of Shone records height energy density than other.

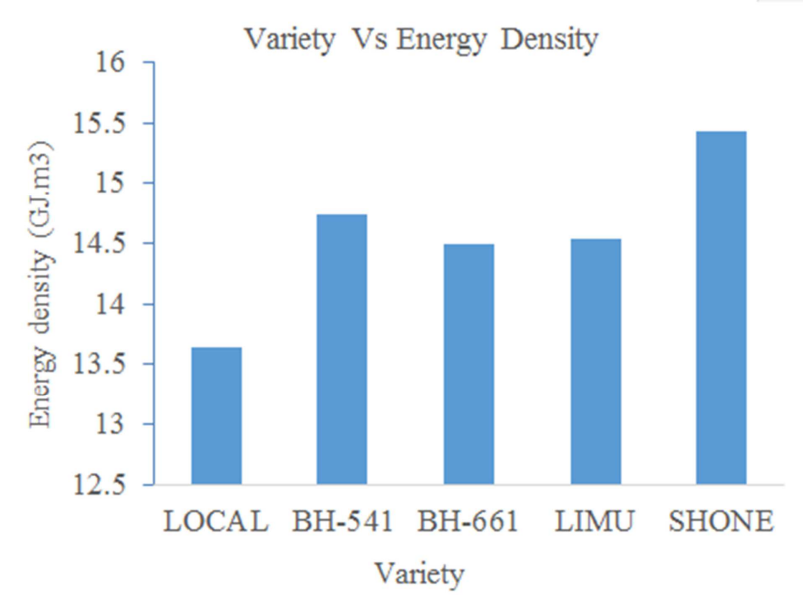

Figure 3. Mean Energetic Density of Briquette in GJ. $M^{-3}$.

In addition, Shone variety is more productive in yield than other when compared with similar production land. Biomass physical feature and size of shone variety corn cob is quite different and its strength is lower than BH-543 and BH-661 varieties. Corn cob briquette HHV is higher than raw corn cob because most of the components that have less stable bonds in the raw corn cob were broken down during carbonization. However, the compounds that have heat resilient bonds remain preserved.

From experimental test result, it can be concluded that HHV of briquette showed an average increase of $58.08 \%$, when it is compared with HHV of raw corn cob. This is the main reason for the increase in energetic density of corn cob briquette as compared to raw corn cob, because this is a multiplication between density and HHV. Thus, as portion of the corncob is degraded during carbonization as well as briquette density is less than the corn cob, but briquette HHV is significantly 
greater, resulting in a higher energetic density of briquette.

\subsubsection{Proximate Analysis}

Table below illustrated the mean values of proximate analysis of the corn cob briquette. The analysis included fixed carbon, volatile matter and ash content of five varieties of corn cob briquettes. According to Pallavi, 2013 [23] studied and reported that fixed carbon of carbonized briquette become more suitable for domestic application if fixed carbon content become $80.5 \%$. The higher the fixed carbon content of a fuel, the greater the calorific value the smaller the volatile matter, the lower the ash and moisture content and the better the quality of the fuel as stated by Moore and Johnson, 1999 [24].

However here in my experiment, average moisture content, volatile matter, ash content and fixed carbon ranged from between 7.94 to $9.86 \%, 15.48$ to $16.86 \%, 22.68$ to $28.97 \%$ and 46.50 to $52.32 \%$ respectively for all varieties. The study insisted or encouraged farmers to utilize carbonized corncob as alternative material for energy resource. Briquettes production will be more attract and engage many human power for job creation. This will increase the sources of energy for domestic and industrial use in developing economy.

Table 1. Mean values of charcoal fixed carbon, volatile matter, and ash contents, in percentage.

\begin{tabular}{lllll}
\hline Variety & Moisture\% & Volatile\% & Ash\% & Fixed carbon\% \\
\hline Local & 8.24 & 15.52 & 26.75 & 49.46 \\
BH-541 & 9.58 & 14.46 & 28.86 & 46.53 \\
BH-661 & 8.53 & 15.02 & 28.87 & 47.47 \\
Limu & 8.51 & 13.47 & 26.48 & 51.48 \\
Shone & 7.86 & 16.78 & 23.12 & 52.22 \\
\hline
\end{tabular}

Akintaro \& Musa, 2017 [20] obtained average moisture content, volatile matter, ash content and fixed carbon of corn cob briquette ranged from between 4.43 to $7.62 \%, 10.31$ to $16.48 \%, 3.03$ to $5.06 \%$ and 72.68 to $81.30 \%$ respectively. Moisture content and volatile matter of this study were agreed with least difference. Whereas in case of ash content and fixed carbon quite difference occurred throughout study.

\section{Conclusion \& Recommendation}

Corn cob carbonization technology enabled to carbonize raw corn cob with good conversion efficiency. Carbonizing corn cob minimizes or manages coal tar and smoke released during combustion that directly connected to health hazards. Furthermore carbonizing process increases energy density of corn cob. Wherever corn cob are abundantly available, employing this technology, assistance to redirect and encourage utilization of corn cob charcoal as substitute to wood and wood charcoal.

At this time raw corncob of all varieties were carbonized and briquette were prepared for characterizing them. Among the varieties, shone variety shows height performance both in proximate analysis and energy density. Energy density was calculated or estimated from bulk density and heating value of biomass fuel. In addition, this variety was more productive in yield than other when compared with similar production land. Biomass physical feature and size of shone variety corn cob is quite different and its strength is lower than BH-543 and BH-661 varieties.

So far significant effort have been made in inducing the farmer to utilize corn cob carbonization technology so as to redirecting ones focus of attention to this issue and encouraging the utilization of char of corn cob as a substitute to wood and wood charcoal. However it could not go further due to some drawback existed in carbonizing technology. But at recent the problem was get solved. Corn cob carbonization simulated the coalification process to produce char with a high energy density through the omission of the energy-intensive drying process.

It can be recommended that carbonization technology minimize loss of energy occurred due to inefficient of way of processing and insufficient system to satisfy energy demand. Moreover it encourages farmers residing in maize belt areas as source of additional financial income by supplying the urban market with charcoal of corncob. This could play great deal in climate mitigation program by minimizing forest resource continual destruction and suffering from climatic irregularities.

\section{Acknowledgements}

The authors would like to thank laboratory technicians of Alternative Energy Technologies Development and Promotion Directorate, Ministry of Water, Irrigation and Energy of Ethiopia for their great contribution. All laboratory works and briquette preparation were performed in the directorate workshop.

In addition would to thank Energy Engineering Team of Bako Agricultural Engineering Research Center for data collection that supported manuscript, contribution for preparation of paper and valuable comments and suggestions on research work and technicians of metal workshop particularly Mr. Legese Gejeha and Mr. Chala Daka for their emanate contribution for construction of carbonization technology.

Finally, my thank goes to all stuff of Oromia Agricultural Research Institute for their financial support and comments in reviewing the manuscript throughout our chain.

\section{References}

[1] Girard P. Charcoal production and use in Africa: what future? Unasylva, an international journal of forestry and forest industries, FAO: Food and Agriculture Organization of the United Nations, Rome, 2002, 211 (53).

[2] Madon G. An assessment of tropical dry-land forest management in Africa: what are its lessons? Presented at the World Bank seminar Communication for Village Power, Empowering People and Transforming Markets, DC, Washington, USA, 4-8 December 2000.

[3] Samson T. An introductory to fuel saving stoves (Training manual) GTZ-HEPNR, Training provided in January 2000, Addis Ababa, Ethiopia. 2000. 
[4] Kang S., Li X., Fan J. and Chang J. Characterization of hydro chars produced by hydrothermal carbonization of lignin, cellulose, D-xylose, and wood meal. Ind. Eng. Chem. Res. 2012, 51, pp 9023-9031.

[5] Bhagwaro Shinde V. \& Singaravelu M. Bulk density of biomass and particle density of their briquettes, International Journal of Agricultural Engineering, 2014, 7 (1), pp 221-224.

[6] Enweremadu C. C., Ojediran J. O., Ogunwa A. and Afolabi L. O. Determination of the energy potentials of orange pomace. Science Focus, 2004, 8 (1): pp 5-9.

[7] Oladeji J T. Comparative Fuel Characterization of Briquettes produced from Two Species of Corncob. Researcher, ISSN: 1553-9865, 2011, 3 (4): pp 1-4. http://www.sciencepub.net

[8] Patomsok W. Physical Characteristics of Maize Cob Briquette under Moderate Die Pressure, American Journal of Applied Sciences, 2007, 4 (10), pp 995-998.

[9] Amaya A, Medero N, Tancredi N, Silva H and Deiana C. Activated carbon briquettes from biomass materials. Bio-resource Technology, 2007, 98 (8), pp 1635-1641.

[10] Suhartini S, Hidayat N and Wijaya S. Physical properties characterization of fuel briquette made from spent bleaching earth, Biomass, Bioenergy, 2011, 35, pp 4209-4214.

[11] Oladeji J. T. Fuel characterization of briquettes produced from corncob and rice husk resides, Pacific Journal of Science and Technology, 2010, 11 (1), pp 101-106.

[12] Legese G., A. S. Langyintuo, W. Mwangi \& Jaleta M. Determinants of Adoption of Improved Drought Tolerant Maize Varieties and Their Implication for Household Food Security in Drought Prone Areas, Ethiopian Journal of Agricultural Economics, 2011, 8 (1), pp 105-132.

[13] Central Statistical Agency of Ethiopia (CSA). Agricultural sample survey: Report on area and production of crops, National Statistics, Addis Ababa, Ethiopia, 2010.

[14] Liu S., Wang Q., Yang G., and Chen J. Sodium Hydrogen Sulfite Pretreatment of wood pulp waste for enrichment of enzymatic efficiency, 2014, 9 (4), pp 6386-6396.

[15] Yang G. H., Jahan M. S., Ahsan L., Zheng, L. J. and Ni Y. Influence of the dilute on the extraction of acetic acid from the pre-hydrolysis liquor of Kraft based dissolving pulp production process by tertiary, Sep. purify Technol. 120, 2013 a, pp 341-345, DOI: 10.1016/j. seppur 2013.10.004.

[16] Yang G. H., Jahan M. S., Ahsan L., Zheng L. J. and Ni Y. Recovery of acetic acid from pre-hydrolysis liquor of hard wood Kraft- based dissolving pulp production process by reactive extraction with trisoocty lamina Bio-resource, Technol. 138, 2013 b, pp 253-258. DOI: 10.1016/j.biortech.2013.03.16.

[17] Parshetti G. K., Liu Z., Jain A., Srinivasan M., and Balasubramaian R. Hydrothermal Carbonization of sewage sludge for energy production with coal, Fuel 111, 2013, pp 201-210. DOI: 10.1016/j.fuel.2013.04.052.

[18] Kaliyan N., Morey RV., White M. D. and Doering A. Roll press briquetting and pelleting of corn Stover and switchgrass, Trans. ASABE 52, 2009, pp 543-555.

[19] Santos R. C. D., Carneiro A. D. O., Castroetal A. F. M. Correlation of quality parameters of wood and charcoal of clones of eucalyptus, Forest Sciences, 2011, 90 (2), pp. 221-230.

[20] Akintaro A. O., Musa A. I., Ajobo J. A. and Oyewusi T. F. The Potentials of Using Carbonized Corncob to Produced Briquettes as an Alternative to Fuelwood, FUTA Journal of Research in Sciences, 2017, 13 (1), pp 137-145.

[21] Adetogun A. C., Ogunjobi K. M. and Are D. B. Combustion Properties of Briquettes Produced From Maize Cob of Different Particle Sizes, Journal of Research in Forestry, Wildlife and Environmental, 2014, 6 (1), pp 28-38.

[22] Oladeji J. T. \& Enweremadu C. C. The Effects of Some Processing Parameters on Physical and Densification Characteristics of Corncob Briquettes, International Journal of Energy Engineering, DOI: 10.5923/j.ijee.20120201.04, 2012, 2 (1), pp 22-27.

[23] Pallavi H. V., Srikantaswamy S., Kiran B. M., Vyshnavi D. R. and Ashwin C. A. Briquetting Agricultural Waste as an Energy Source. Journal of Environmental Science, Computer Science and Engineering \& Technology, 2013, 2 (1), pp 160-172.

[24] Moore W. and Johnson D. Procedures for the Chemical Analysis of Wood and Wood Products. Forest Products Laboratory Department of Agriculture. Madison, U. S. A., 1999. 